\title{
The impact of knowledge about diabetes, resilience and depression on glycemic control: a cross-sectional study among adolescents and young adults with type 1 diabetes
}

\author{
Fabio R Munhoz Santos ${ }^{1 *}$, Viviane Bernardo ${ }^{1}$, Monica A L Gabbay², Sergio A Dib² and Daniel Sigulem
}

\begin{abstract}
Background: The purpose of this study is to evaluate the relationship between glycemic control and the factors of knowledge about diabetes, resilience, depression and anxiety among Brazilian adolescents and young adults with type 1 diabetes.

Methods: This cross-sectional study included 85 adolescents and young adults with type 1 diabetes, aged between 11-22 years, with an average age of $17.7 \pm 3.72$ years. Glycemic control degree was evaluated through HbA1c. To assess psychosocial factors, the following questionnaires were used: resilience (Resilience Scale, RS) and anxiety and depression (Hospital Anxiety and Depression Scale, HADS). The Diabetes Knowledge Assessment Scale (DKNA) was used to assess knowledge about diabetes.

Results: Significant correlations were found between $\mathrm{HbA} 1 \mathrm{c}$ and resilience, anxiety and depression. Multiple linear regression analysis revealed that the only variable which presented significant association with the value of $\mathrm{HbA} 1 \mathrm{c}$ was depression.

Conclusions: Depression has a significant association with higher HbA1c levels, as demonstrated in a regression analysis. The results suggest that depression, anxiety and resilience should be considered in the design of a multidisciplinary approach to type 1 diabetes, as these factors were significantly correlated with glycemic control. Glycemic control was not correlated with knowledge of diabetes, suggesting that theoretical or practical understanding of this disease is not by itself significantly associated with appropriate glycemic control $(\mathrm{HbA} 1 \mathrm{c} \leq 7.5 \%)$.
\end{abstract}

Keywords: Glycemic control, Type 1 diabetes, Psychosocial factors, Depression, Resilience

\section{Background}

The importance of tight blood glucose control for the subsequent prevention of diabetes complications is well established: higher HbA1c levels in type 1 diabetes are associated with conditions such as retinopathy and nephropathy $[1,2]$. Despite the development of diabetes therapy during recent decades, the quality of diabetes care, in general requires improvement. Effective educational programs aimed at managing glycemic control need to

\footnotetext{
* Correspondence: fabiomunhoz@hotmail.com

1 Department of Health Informatics, Universidade Federal de São Paulo, Rua Botucatu, 862, São Paulo CEP:04023-062, SP, Brazil

Full list of author information is available at the end of the article
}

address not only knowledge about the procedures, but also psychosocial factors [1].

In order to contribute to the development of educational activities for young people with type 1 diabetes, as well as promote knowledge about diabetes, this study assesses factors that have recognized scope and impact on glycemic control: on the one hand, depressive and anxiety symptoms; and on the other, resilience, which encompasses many protective factors such as social support, hope, selfefficacy, problem-focused strategies, etc.

The knowledge each patient has about diabetes is a basic element in educational programs for type 1 diabetes

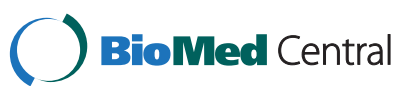


patients [3]. The patient is required to have basic knowledge about insulin, carbohydrate counting, diet, etc. Knowledge is one of many important variables involved in diabetes education. A study has demonstrated the positive impact that knowledge has on glycemic control [4]. However, others suggest that the level of knowledge about diabetes is not a predictor of good glycemic control and generally recommend the need for further research in this field $[5,6]$.

The relationships between psychosocial factors and glycemic control in diabetic patients are well described in the literature. It is apparent that the chronicity of type 1 diabetes and the demands for management provide a fertile environment for adjustment problems. One of the most studied psychosocial factors in this area is depression. Depressive symptoms occur at higher levels in patients with diabetes than in the general population and are also associated with higher HbA1c levels [7-9]. Patients with diabetes who have clinical depression present higher rates of clinical complications, hospitalization and health expenditures [10]. In patients with type 1 diabetes, depression has a significant influence on treatment adherence and health outcomes [11].

Resilience is a psychosocial factor that has been gaining academic importance. It is a broad concept that encompasses an individual's resources for adequately dealing with adversity and achieving positive results in such situations. Resilience involves optimism in the face of situations, strategies for problem-focused resolution, self-efficacy, and self-confidence [12]. In people with physical illnesses, resilience relates to factors such as self-care, adherence to treatment, quality of life as related to health, illness perception, pain perception and adherence to physical activity [13]. In a study of individuals with type 2 diabetes, DeNisco found that HbA1c levels and resilience scores had a significant negative correlation, suggesting that resilience may influence glycemic control [14]. In young people with diabetes, resilience is a protective factor, expressed to different degrees in each patient, when facing stressful situations [15].

The association of depression and diabetes mellitus is supported by numerous studies [6-10]. Some studies have evaluated the extent of resilience in diabetes patients [12-15]. However, we found no studies that simultaneously evaluated the relationship between glycemic control and knowledge about diabetes, depressive symptoms, anxiety and resilience in type 1 diabetes, particularly in young Brazilians. By better understanding the complex relationship between these factors and glycemic control, the present study will contribute to a greater understanding of the factors related to glycemic control in young people with type 1 diabetes and may also be useful for planning and implementing educational activities for such patients.
Thus, the present study aimed to (A) evaluate the correlation between glycemic control and knowledge about diabetes, resilience, anxiety, and depression in young Brazilians with type 1 diabetes and (B) verify the significant effect of each variable on glycemic control in a multiple linear regression analysis.

\section{Methods}

\section{Research design}

This was a cross-sectional study that included 90 adolescents and young adults with type 1 diabetes who were randomly invited to participate. These patients were being followed up at the outpatient public division of the Diabetes Center of the Federal University of São Paulo, São Paulo, Brazil. After Institutional Ethical Committee approval, interviews were conducted from May to September 2012. The inclusion criteria were as follows: diagnosis of type 1 diabetes, no mental disorders, absence of visual or hearing disabilities. The patients recruited had long-term type 1 diabetes diagnosed according to the American Diabetes Association criteria [16]. During the study, as in real life, they continued to adjust insulin doses based on glucose control, diet and exercise, according to the Brazilian Diabetes Society guidelines [17].

Of the invited patients, 85 (94.3\%) agreed to participate in this study and $5(5.7 \%)$ refused to participate, either because they did not want to participate or they lacked sufficient time to be interviewed. The age of the participants ranged from 11- 22 years old, with an average age of $17.7 \pm 3.72$ y.o (mean $\pm S D$ ).

After signed consent was obtained, demographic data and the time of diagnosis were also collected. Informed consent was obtained from the patients over 18 years of age and from the family responsible, for patients under 18. On the same occasion, glycated hemoglobin (HbA1c) was evaluated and questionnaires were administered to assess the following variables: knowledge about diabetes, resilience, anxiety and depression.

All questionnaires were completed online at the Diabetes Center, and the data were stored in a database on the University's server. The interviews took between 20 and 30 minutes and always occurred in the presence of a researcher and an assistant.

Table 1 describes the demographic profile of the sample. Among the 85 patients aged between 11-23 years old, 40 (53\%) were women. Regarding their level of education, which relates to their instruction degree, 16 (19\%) either were in progress or had completed the elementary school, 49 (57\%) and 20 (24\%) for secondary school and higher education, respectively. The duration of diabetes among patients was: $10(11 \%)$ had been diagnosed in the last two years; 29 (34\%) had been diagnosed between two and six years; and 46 (55\%) had lived with a diagnosis of diabetes for over 6 years. 
Table 1 Demographic profile of 85 type 1 diabetes patients

\begin{tabular}{ccc}
\hline Characteristic & $\mathbf{n}$ & $\%$ \\
\hline $\begin{array}{c}\text { Gender } \\
\text { Women } \\
\text { Age }\end{array}$ & 45 & $53 \%$ \\
11-18 years & 41 & \\
$>18-23$ years & 44 & $48 \%$ \\
Educational Level & & $52 \%$ \\
Primary Education & 16 & \\
High School & 49 & $19 \%$ \\
University & 20 & $57 \%$ \\
Duration of Diabetes & & $24 \%$ \\
0-2 years & 10 & $11 \%$ \\
$>2-6$ years & 29 & $34 \%$ \\
$>6$ years & 46 & $55 \%$ \\
\hline
\end{tabular}

\section{Methodology}

Main variable

Glycemic control The HbA1c was used as a parameter in order to evaluate the degree of glycemic control. Tests were performed within the 4 months preceding the interview. HbA1c was evaluated by high-performance liquid chromatography (HLPC), using a Tosoh G7 Auto HPLC. This method is certified by the National Glycohemoglobin Standardization Program - USA.

\section{Secondary variables}

Knowledge about diabetes The Diabetes Knowledge Scale (DKN-A), developed by Beeney in 2000, was used to assess the level of knowledge about diabetes [18]; it was validated for Brazilian Portuguese by Torres et al. [19] and was also validated for use in young people and adolescents by Fitzgerald in 1998 [20].

Resilience The resilience scale (RS) developed by Wagnild and Young in 1993 [21], and validated and adapted to Portuguese by Pesce in 2005 [22], was used. The RS questionnaire was also validated for use in young people and adolescents by Ahern in 2006 [23].

Anxiety and depression Depressive symptoms were assessed using the Hospital Anxiety and Depression Scale (HADS), developed in 1983 by Zigmond and Snaith [24]. The scale consists of 14 questions; 7 items for depression (HADS-D) and 7 for anxiety (HADS-A). The scores for each subscale range from $0-21$. This tool was validated for Portuguese by Gorenstein in 2000 [25], and was validated for use in young people and adolescents by White et al. in 1999 [26].

\section{Statistical analysis}

Correlations between quantitative data were estimated using Pearson correlation. For ordinal data, the authors used the Spearman coefficient. A multiple linear regression model was prepared to simultaneously evaluate the effects of the factors (knowledge about diabetes, resilience, depression and anxiety) on HbA1c. The level of significance was set at $p \leq 0.05$. Data were analyzed using the SPSS software package version 18.0.

\section{Results}

The HbA1c level in subjects in the present study was $9.3 \pm 2$. $3 \%$ (mean $\pm \mathrm{sd}$ ), ranging from 5.8 to $16.1 \%$. Of the subjects, 65 (76.5\%) had HbA1c levels $>7.5 \%$, and 20 $(23.5 \%) \leq 7.5 \%$.

Relationships between $\mathrm{HbA} 1 \mathrm{c}$ and the variables evaluated Table 2 presents the correlations between the study variables and HbA1c levels.

\section{Impact of each variable on glycemic control}

Table 3 shows the results of the multiple linear regression analysis, assessing the impact of each variable on HbA1c.

\section{Discussion}

The results of the present study among Brazilian adolescents and young adults with type 1 diabetes show that $76.5 \%$ of the subjects had an HbA1c level above $7.5 \%$. In this sample, the mean HbA1c was $9.3 \pm 2.3 \%$ (mean $\pm \mathrm{sd}$ ). The goal of treatment for young people and adolescents with type 1 diabetes is an HbA1c value of $7.5 \%$ or less [2]. A high percentage of this study's population had suboptimal glycemic control (HbA1c $\geq 7.5 \%$ ), and thus was within the risk range for the development of diabetic

\begin{tabular}{|c|c|c|c|c|}
\hline & $\begin{array}{c}\text { Knowledge } \\
\text { (DKNA) }\end{array}$ & $\begin{array}{l}\text { Resilience } \\
\text { (RS) }\end{array}$ & $\begin{array}{l}\text { Anxiety } \\
\text { (HADS-A) }\end{array}$ & $\begin{array}{c}\text { Depression } \\
\text { (HADS-D) }\end{array}$ \\
\hline \multirow[t]{2}{*}{$\mathrm{HbA1c}$} & -0.06 & -0.22 & 0.25 & 0.33 \\
\hline & $(0.600)$ & $(0.048)^{*}$ & $(0.022)^{*}$ & $(0.002)^{*}$ \\
\hline \multirow[t]{2}{*}{ Knowledge (DKNA) } & - & 0.20 & 0.05 & 0.02 \\
\hline & & $(0.065)$ & $(0.642)$ & $(0.876)$ \\
\hline \multirow[t]{2}{*}{ Resilience (RS) } & - & - & -0.36 & -0.32 \\
\hline & & & $(<0.001)^{* *}$ & $(0.003)^{*}$ \\
\hline \multirow[t]{2}{*}{ Anxiety (HADS-A) } & - & - & - & 0.51 \\
\hline & & & & $(<0.001)^{* *}$ \\
\hline
\end{tabular}

Data represent Pearson correlation coefficients and their statistical significance (in parentheses). HbA1c: glycated hemoglobin, DKNA: Diabetes Knowledge Assessment Scale, HADS-A: HADS anxiety score, HADS-D: HADS depression score. ( $\left.{ }^{*} \mathrm{p}<0.05 ;{ }^{* *} \mathrm{p}<0.001\right)$. 
Table 3 Impact of factors (knowledge, resilience depression and anxiety) on HbA1c levels in a multiple linear regression model in the patients sample $(n=85)$

\begin{tabular}{ccccc}
\hline Factor & $\boldsymbol{B}$ & $\mathbf{9 5 \%} \mathrm{Cl}$ & $\boldsymbol{p}$ & $\boldsymbol{r}_{\text {(partial) }}$ \\
\hline Constant & 9.97 & - & - & \\
Knowledge (DKNA) & -0.05 & -0.24 to 0.14 & 0.603 & -0.06 \\
Resilience (RS) & -0.04 & -0.12 to 0.04 & 0.306 & -0.12 \\
Anxiety (HADS-A) & 0.07 & -0.10 to 0.24 & 0.418 & 0.09 \\
Depression (HADS-D) & 0.20 & 0.02 to 0.37 & $0.031^{*}$ & 0.24 \\
\hline
\end{tabular}

$B$ is the estimate of how much a one-unit increase in a factor is associated with the variation in $\mathrm{HbA1c}$ levels. The partial " $r$ " represents the correlation of the factor with $\mathrm{HbA} 1 \mathrm{c}$ after considering the effect of the other terms in the model. HbA1c: glycated hemoglobin, DKNA: Diabetes Knowledge Assessment Scale, HADS-A: HADS anxiety score, HADS-D: HADS depression score. $\left({ }^{*} \mathrm{p}<0.05\right)$.

complications [2]. This finding confirms the need for constant efforts to understand the factors that have an impact on glycemic control, aiming at promoting educational activities for this population.

Among the variables assessed, only depressive symptoms were significantly associated with high $\mathrm{HbA} 1 \mathrm{c}$ in a regression analysis. This result is consistent with the literature and corroborates studies which show a link between depression, higher HbA1c levels, hospitalization and complications [7-10,27]. This is probably because depression carries low self-esteem and neglect of self-care behaviors. We can infer that a patient with depressive symptoms will not take care of glycemic monitoring, and may become careless with diet and physical activities.

The anxiety scores in the study subjects were significantly correlated with $\mathrm{HbA1c}$, but were not significantly associated in a multiple regression analysis. Shabam et al. report a different outcome in type 1 diabetes adults via a multiple regression analysis, showing anxiety as a predictor of high HbA1c; they also used the HADS [27]. Anxiety symptoms are more common in patients with diabetes than in the general population [28]. The results of these studies converge on the same implication: anxiety is a significant factor that must be taken into account and addressed in glycemic control programs.

The results of the present study indicate that resilience is also significantly correlated with HbA1c. This result is concordant with the preliminary study of Jaser, which shows that good glycemic control $(\mathrm{HbA1c} \leq 7.5 \%)$ is associated with resilience and the use of appropriate coping strategies (e.g., problem solving, emotional expression, acceptance, and social support) [29]. In a literature review, Bradshaw states that resilience can be increased in patients with diabetes; although these resilience trainings do not demonstrate a direct impact on glycemic control, they result in improvements in selfcare behaviors [30]. It can be inferred from these results that training in resilience should be incorporated into programs for this population, covering topics such as: optimal sleep, physical activity, appropriate food choices, blood glucose monitoring, compliance with medication, self-efficacy and social support.

In this study, the level of knowledge about diabetes was not significantly correlated with HbA1c. This indicates that both well- and poorly-controlled subjects exhibit similar levels of basic knowledge about diabetes. Previous studies also found no correlation between knowledge about diabetes and glycemic control [5,6,31].

Although knowledge is not significantly associated with glycemic control, it is a prerequisite for a patient to perform appropriate self-care [4]. Knowledge education per se may not, however, be the major operative factor in improving control of diabetes. Strategies to provide information must be combined with other behavioral strategies to motivate and help patients effectively manage their diabetes.

\section{Study limitations}

There are a few important limitations to this study. The first limitation is the inability to assess causal factors due to the study's cross-sectional design. Another limitation is that variables known to have an effect on glycemic control were not examined in the current research, for example, social networks, self-efficacy, self-esteem, and family environment.

Future longitudinal studies are needed to explore the causal relationships of these factors, as well as studies assessing the effectiveness of interventions that contribute to better glycemic control in this population.

\section{Conclusions}

The high percentage of patients with higher HbA1c levels $(76.5 \%$ with $\mathrm{HbA1c}>7.5 \%)$ found in the present study implies that there is a need for effective multidisciplinary actions to improve the glycemic control of these adolescents and young adults with type 1 diabetes. It is important that diabetes care groups develop and evaluate specific programs for this population. Glycemic control was not correlated with knowledge of diabetes, suggesting that only theoretical or practical understanding about this disease is not associated with good glycemic control. It can be concluded that information by itself is not significantly associated with good control.

As this study has shown, depression has a significant association with higher HbA1c levels and anxiety and resilience are significantly correlated with glycemic control. These factors should be addressed in educational programs aimed at improving glycemic control in adolescents and young adults with type 1 diabetes. 


\section{Abbreviations}

HbA1c: Glycated hemoglobin; HLPC: High-performance liquid chromatography; HADS: Hospital anxiety and depression scale; DKN-A: Diabetes knowledge scale; RS: Resilience scale; HHI: Herth hope index.

\section{Competing interests}

The authors declare that they have no competing interests.

\section{Authors' contributions}

FRMS wrote the paper, collected data and performed statistical analyses; SAD and MALG assisted in patient recruitment; DS, VB and SAD assisted in conception of the research hypothesis and reviewed the manuscript. All authors read and approved the final manuscript.

\section{Acknowledgments}

This research was financially supported by FAPESP, Fundação de Amparo à Pesquisa do Estado de São Paulo. The Department of Health Informatics, Universidade Federal de São Paulo, provided the administrative infrastructure for the study. The Diabetes Center, Universidade Federal de São Paulo, also supported the project by allowing patients with diabetes mellitus type 1 followed by the Centre to participate.

\section{Author details}

'Department of Health Informatics, Universidade Federal de São Paulo, Rua Botucatu, 862, São Paulo CEP:04023-062, SP, Brazil. Endocrinology Division, Departament of Medicine, Universidade Federal de São Paulo, São Paulo, Brazil.

Received: 6 March 2013 Accepted: 21 September 2013 Published: 28 September 2013

\section{References}

1. American Diabetes Association: Standards of medical care in diabetes-2008. Diabetes Care 2008, 31(Suppl 1):S12-S54.

2. McCarter RJ, Hempe JM, Gomez R, Chalew SA: Biological variation in $\mathrm{HbA} 1 \mathrm{c}$ predicts risk of retinopathy and nephropathy in type 1 diabetes. Diabetes Care 2004, 27:1259-1264.

3. Miller LV, Goldstein J, Nicolaisen G: Evaluation of patients' knowledge of diabetes self-care. Diabetes Care 1978, 1:275-280.

4. Heisler M, Piette JD, Spencer M, Kieffer E, Vijan S: The relationship between knowledge of recent $\mathrm{HbA} 1 \mathrm{c}$ values and diabetes care understanding and self-management. Diabetes care 2005, 28:816-822.

5. Beeney LJ, Dunn SM: Knowledge improvement and metabolic control in diabetes education: approaching the limits. Patient Educ Couns 1990 16:217-229

6. Bloomgarden ZT, Karmally W, Metzger MJ, Brothers M, Nechemias C, Bookman J, Brown W, et al: Randomized, controlled trial of diabetic patient education: improved knowledge without improved metabolic status. Diabetes care 1987, 10:263-272.

7. Anderson RJ, Freedland KE, Clouse RE, Lustman PJ: The prevalence of comorbid depression in adults with diabetes: a meta-analysis. Diabetes Care 2001, 24:1069-1078.

8. Stewart SM, Rao U, Emslie GJ, Klein D, White PC: Depressive symptoms predict hospitalization for adolescents with type 1 diabetes mellitus. Pediatrics 2005, 115:1315-1319.

9. Hood KK, Huestis S, Maher A, Butler D, Volkening L, Laffel LMB: Depressive symptoms in children and adolescents with type 1 diabetes. Diabetes Care 2006, 29:1389-1391.

10. Egede LE, Zheng D, Simpson K: Comorbid depression is associated with increased health care Use and expenditures in individuals with diabetes. Diabetes Care 2002, 25:464-470.

11. Kyrios M, Nankervis A, Reddy P, Sorbello LM: The relationship of depression to treatment adherence, quality of life and health outcomes in type 1 diabetes mellitus. E-J App/ Psychol 2006, 2:3-14.

12. Yi JP, Vitaliano PP, Smith RE, Yi JC, Weinger $K$ : The role of resilience on psychological adjustment and physical health in patients with diabetes. BrJ Health Psychol 2008, 13:311-325.

13. Stewart $D E$, Yuen $T$ : A systematic review of resilience in the physically ill. Psychosomatics 2011, 52:199-209.

14. DeNisco S: Exploring the relationship between resilience and diabetes outcomes in African Americans. J Am Acad Nurse Pract 2011, 23:602-610.
15. Hilliard ME, Harris MA, Weissberg-Benchell J: Diabetes resilience: a model of risk and protection in type 1. Curr Diab Rep 2012, 12:739-748.

16. American Diabetes Association: Diagnosis and classification of diabetes mellitus. Diabetes Care 2008, 31:S55-S60.

17. Diretrizes da sociedade brasileira de diabetes; 2009. http://www.diabetes.org br/attachments/diretrizes09_final.pdf.

18. Beeney LJ, Dunn SM, Welch G: Measurement of diabetes knowledge: the development of the DKN scales. In Handbook of psychology and diabetes. Edited by Bradley C, Bradley C. Amsterdam: Harwood Academic Publishers; 2001:159-189.

19. Torres HC, Hortale VA, Schall VT: Validação dos questionários de conhecimento (DKN-A) e atitude (ATT-19) de Diabetes Mellitus. Revista Saúde Pública 2005, 39:906-911.

20. Fitzgerald JT, Funnell MM, Hess GE, Barr PA, Anderson RM, Hiss RG, Davis WK: The reliability and validity of a brief diabetes knowledge test. Diabetes Care 1998, 21:706-710.

21. Wagnild GM, Young HM: Development and psychometric evaluation of the resiliency scale. J Nurs Manag 1993, 1:165-178.

22. Pesce RP, Assis SG, Avanci JQ, Santos NC, Malaquias JV, Carvalhaes R: Adaptação transcultural, confiabilidade e validade da escala de resiliência. Caderno de Saúde Pública 2005, 21:436-448.

23. Ahern NR, Kiehl EM, Lou Sole M, Byers J: A review of instruments measuring resilience. Issues Compr Pediatr Nurs 2006, 29:103-125.

24. Zigmond AS, Snaith RP: The hospital anxiety and depression scale. Acta Psychiatr Scand 1983, 67:361-370.

25. Gorenstein C, Andrade LHSG, Zuardi AW: Escalas de avaliação clínica em psiquiatria e psicofarmacologia. São Paulo: Lemos-Editorial; 2000.

26. White $D$, Leach $C$, Sims $R$, Cottrell D: Validation of the HADS in adolescents. Brit J Psychiatr 1999, 175:452-454.

27. Shaban C, Fosbury JA, Cavan DA, Kerr D, Skinner TC: The relationship between generic and diabetes specific psychological factors and glycaemic control in adults with type 1 diabetes. Diabetes Res Clin Pract 2009, 85:e26-e29.

28. Tuncay T, Musabak I, Gok DE, Kutlu M: The relationship between anxiety, coping strategies and characteristics of patients with diabetes. Health Qual Life Outcomes 2008, 6:79.

29. Jaser SS, White LE: Coping and resilience in adolescents with type 1 diabetes. Child Care Health Dev 2011, 37:335-342.

30. Bradshaw BG, Richardson GE, Kulkarni K: Thriving with diabetes: an introduction to the resiliency approach for diabetes educators. Diabetes Educ 2007, 33:643.

31. Dunn SM, Hoskins PL, Turtle JR: Knowledge and attitude change as predictors of metabolic improvement in diabetes education. Soc Sci Med 1990, 31:1135-1141.

doi:10.1186/1758-5996-5-55

Cite this article as: Santos et al:: The impact of knowledge about diabetes, resilience and depression on glycemic control: a cross-sectional study among adolescents and young adults with type 1 diabetes. Diabetology \& Metabolic Syndrome 2013 5:55.

\section{Submit your next manuscript to BioMed Central and take full advantage of:}

- Convenient online submission

- Thorough peer review

- No space constraints or color figure charges

- Immediate publication on acceptance

- Inclusion in PubMed, CAS, Scopus and Google Scholar

- Research which is freely available for redistribution 